\title{
Fatal Hypocalcaemia Due to Hungry Bone Syndrome with Secondary Refractory HyperParathyroidism after Parathyroidectomy: A Case Report
}

\author{
Corina Pop Radu ${ }^{1,2}$, Valentin Daniealopol ${ }^{3}$, Ario Santini ${ }^{2,4}$, Ruxandra Darie ${ }^{3}$, Daniela \\ Tatiana Sala2, 3 \\ 1 Endocrinology Department, Mures County Emergency Hospital, Targu Mures, Romania \\ 2 University of Medicine, Pharmacy, Science and Technology of Targu Mures, Romania \\ $32^{\text {nd }}$ Surgery Department, Mures County Emergency Hospital, Targu Mures, Romania \\ ${ }^{4}$ Hon Fellow, University of Edinburgh, United Kingdom
}

\begin{abstract}
Introduction: Hungry bone syndrome (HBS) refers to the rapid, profound, and prolonged hypocalcaemia associated with hypophosphatemia and hypomagnesaemia, and is exacerbated by suppressed parathyroid hormone (PTH) levels, which follows parathyroidectomy in patients with severe primary hyperparathyroidism (PHPT) and preoperative high bone turnover. [1]

Case report: This report concerns a dialysed patient who underwent surgical treatment for secondary refractory hyperparathyroidism. Haemodialysis was carried out pre-operatively, and subsequently, a total parathyroidectomy with auto-transplantation of parathyroid tissue in the sternocleidomastoid muscle (SCM) was performed. Rapid and progressive hypocalcaemia symptoms developed during the second day postoperatively. Acute cardiac symptoms with tachyarrhythmia, haemodynamic instability and finally asystole occurred, which required cardiopulmonary resuscitation (CPR). The ionic calcium level was $2.2 \mathrm{mg} / \mathrm{dL}$ being consistent with a diagnosis of HBS. A second cardiac arrest unresponsive to CPR followed an initial period of normal sinus rhythm. Death ensued shortly after. Before death, the ionic calcium was $3.1 \mathrm{mg} / \mathrm{dL}$.

Conclusion: HBS, after parathyroidectomy in patients with secondary hyperparathyroidism (SHPT), may be severe, prolonged and sometimes fatal. Generally, HBS symptomatology is that of a mild hypocalcaemia. It can, however, include heart rhythm disturbances with haemodynamic alterations requiring intensive care measurements and even cardiopulmonary resuscitation. A close clinical and laboratory post-parathyroidectomy monitoring of dialysed patients is of the utmost importance.
\end{abstract}

Keywords: hungry bone syndrome, secondary hyperparathyroidism, cardiac complications

Received: 02 June 2019 / Accepted: 09 September 2019

\section{INTRODUCTION}

Hungry bone syndrome (HBS) denotes to the rapid, profound, and prolonged hypocalcaemia with attendant hypophosphataemia and hypomagnesaemia, and is aggravated by lowered parathyroid hormone $(\mathrm{PTH})$ levels, which follows parathyroidectomy in patients with severe primary hyperparathyroidism (PHPT) and preoperative high bone turnover [1].

This clinical state usually extends for more than three to four days after a parathyroidectomy. It is argued that
HBS is due to the sudden increased calcium influx into the "starved" bone, primed by the decrease of serum parathyroid hormone level (iPTH) post-parathyroidectomy [1]. Hypocalcaemia and HBS are considered either as a postoperative complication or conversely as indicative of a "successful" parathyroidectomy [2]. HBS occurs both after parathyroidectomy performed in primary hyperparathyroidism (PHP) and refractory secondary hyperparathyroidism (SHPT), in the latter case exhibiting more severe and prolonged forms [3]. Several HBS risk factors are described, including el- 
evated preoperative levels of serum iPTH or alkaline phosphatase (AlkPhos) levels, advanced age, preoperative bone damages [4]. HBS symptoms are similar with those of a severe hypocalcaemia: from minor paraesthesia, carpopedal spasms, positive Chvostek and Trousseau signs to convulsions, laryngospasm or acute cardiac dysrhythmias.

The current case report concern the treatment of a dialysed patient with severe HBS which occurred after a total parathyroidectomy performed for secondary refractory hyperparathyroidism, in whom symptoms of hypocalcaemia developed the day following the operation. Heart rhythm disturbances were followed by cardiac arrest. Resuscitation measures were unsuccessful.

\section{CASE REPORT}

A 65 -year-old man, BMI of $33 \mathrm{~kg} / \mathrm{m}^{2}$, was admitted to the Nephrology and Endocrinology/Internal Medicine Department of Harghita General Hospital ( Harghita General Hospital, Miercurea Ciuc, Romania), with generalised weakness, severe pruritus and difficulty walking due to severe left leg pain. His medical history included end-stage renal disease (ESRD) due to adult polycystic disease having been on chronic haemodialysis three times weekly for the past eight and a half years. He had ben diagnosed with secondary hyperparathyroidism approximately three years ago, and since then he had been treated with active metabolites of vitamin $\mathrm{D}$ and bisphosphonates. Longstanding comorbidities such as arterial hypertension, aortic and mitral stenosis, atrial fibrillation, and dyslipidaemia were also not- ed. For these, he had been prescribed antihypertensive, statins and antiplatelet drugs. Additionally, a diagnosis of calciphylaxis was included in the patient's medical papers, without any indication as to who made the initial diagnosis. A few months prior to admission, calcium based phosphate binders had been prescribed; sevelamer carbonate [Renagel, Sanofi, Germany] oral capsules, $800 \mathrm{mg}$ three times daily.

Taking into consideration the refractory secondary hyperparathyroidism with no improvement in the patient condition under the medical treatment stated above, along with the very high levels of iPth, hypocalcaemia and hyperphosphatemia, the attending nephrologist decided to refer the patient to the Second Surgical Department Targu Mures for parathyroidectomy.

Physical examination on admission to the surgical department was non-specific for other endocrine diseases. Blood chemistry showed serum calcium levels of $11.6 \mathrm{mg} / \mathrm{dL}, \mathrm{nv}: 9-10.5 \mathrm{mg} / \mathrm{dL}$, and serum phosphorus levels of $5.6 \mathrm{mg} / \mathrm{dL}, \mathrm{nv}: 2.7-4.5 \mathrm{mg} / \mathrm{dL}$, very high levels of serum intact parathyroid hormone of $1257 \mathrm{pg} / \mathrm{mL}$, nv: $10-65 \mathrm{pg} / \mathrm{mL}$ and high level of alkaline phosphatase of $376 \mathrm{U} / \mathrm{L}, \mathrm{nv}: 40-150 \mathrm{U} / \mathrm{L}$. These data are consistent with a high bone turnover due to uremic osteodystrophy. Table 1 details all laboratory data generated on admission.

Targeted parathyroid imaging, i.e. 99mTc Sestamibi scintigraphy, ordered by the nephrologist in Tg Mures Nuclear Medicine Department, two months earlier, revealed a single image suggestive of parathyroid adenoma, located on the lower part of the right thyroid lobe (Figure 1).

Table 1. First admission, preoperative and postoperative day 1 and 2 laboratory data

\begin{tabular}{|c|c|c|c|c|}
\hline & $\begin{array}{c}\text { First admission } \\
\text { values }\end{array}$ & $\begin{array}{c}\text { Preoperative } \\
\text { values }\end{array}$ & $\begin{array}{c}\text { Postoperative val- } \\
\text { ues (POD 1) }\end{array}$ & $\begin{array}{c}\text { Postoperative values } \\
\text { (POD 2) }\end{array}$ \\
\hline WBC (vn: $\left.3.6-10 \times 10^{3}\right)$ & $8.2 \times 10^{3}$ & $7.1 \times 10^{3}$ & $7.3 \times 10^{3}$ & - \\
\hline Haemoglobin (vn:12-17g/dL) & $14.6 \mathrm{~g} / \mathrm{dL}$ & $14 \mathrm{~g} / \mathrm{dL}$ & $13.7 \mathrm{~g} / \mathrm{dL}$ & $13.5 \mathrm{~g} / \mathrm{dL}$ \\
\hline Haematocrit (vn: 36-54 \%) & $43 \%$ & $42 \%$ & $41 \%$ & $38 \%$ \\
\hline Total calcium (nv: 9-10.5 mg/dL) & $10.9 \mathrm{mg} / \mathrm{dL}$ & $11.6 \mathrm{mg} / \mathrm{dL}$ & $7.3 \mathrm{mg} / \mathrm{dL}$ & - \\
\hline Ionic calcium (nv: $3.8-4.8 \mathrm{mg} / \mathrm{dL}$ ) & - & - & - & $2.2-3.1 \mathrm{mg} / \mathrm{dL}$ \\
\hline Phosphate (nv: 2.7-4.5 mg/dL) & $4.9 \mathrm{mg} / \mathrm{dL}$ & $5.6 \mathrm{mg} / \mathrm{dL}$ & $5.3 \mathrm{mg} / \mathrm{d}$ & - \\
\hline Sodium (nv: 136-145 mmol/L) & $139 \mathrm{mmol} / \mathrm{L}$ & $141 \mathrm{mmol} / \mathrm{L}$ & $136 \mathrm{mmol} / \mathrm{L}$ & $138 \mathrm{mmol} / \mathrm{L}$ \\
\hline Potassium (nv:3.5-5.1 mmol/L) & $4.9 \mathrm{mmol} / \mathrm{L}$ & $5.1 \mathrm{mmol} / \mathrm{L}$ & $6.2 \mathrm{mmol} / \mathrm{L}$ & $6.2 \mathrm{mmol} / \mathrm{L}$ \\
\hline Chloride (nv: 98-107mmol/L) & $104 \mathrm{mmol} / \mathrm{L}$ & $102 \mathrm{mmol} / \mathrm{L}$ & $99 \mathrm{mmol} / \mathrm{L}$ & - \\
\hline AlkPhos (nv: 40-150 U/L) & $364 \mathrm{U} / \mathrm{L}$ & $376 \mathrm{U} / \mathrm{L}$ & $311 \mathrm{U} / \mathrm{L}$ & - \\
\hline iPTH (nv: 10-65pg/mL) & $1198 \mathrm{pg} / \mathrm{mL}$ & $1257 \mathrm{pg} / \mathrm{mL}$ & $47.5 \mathrm{pg} / \mathrm{mL}$ & - \\
\hline Creatinine (nv: 0.72-1.25 mg/dL) & $5.1 \mathrm{mg} / \mathrm{dL}$ & $5.29 \mathrm{mg} / \mathrm{dL}$ & $6.7 \mathrm{mg} / \mathrm{dL}$ & - \\
\hline Glucose (nv: $80-115$ mg/dL) & $81 \mathrm{mg} / \mathrm{dL}$ & $89 \mathrm{mg} / \mathrm{dL}$ & $96 \mathrm{mg} / \mathrm{dL}$ & $85 \mathrm{mg} / \mathrm{dL}$ \\
\hline
\end{tabular}






Fig. 1. 99mTc Sestamibi scintigraphy revealed a right inferior parathyroid adenoma indicative of SHPT.

On admission to the surgical department, the initial preoperative protocol included endocrinology reassessment of the case which confirmed the diagnosis and surgical indication. Cardiological and anaesthesia evaluations were also conducted before surgery. Additionally, preoperative dialysis was carried out the day before surgery.

The patient underwent a total parathyroidectomy with autotransplantation of parathyroid tissue $(\mathrm{tPtx}+\mathrm{AT})$ in sternocleidomastoid muscle (SCM). The weight of the resected parathyroids was $1.42 \mathrm{~g}$.

The procedure was done under general anaesthesia, and no complications occurred.

Immediately after the operation, the serum iPTH level dropped to $47.5 \mathrm{pg} / \mathrm{mL}$, and the patient was transferred to the ward in a stable condition.

The first postoperative supplementation of calcium in dialysate fluid was performed on the first day after the operation (POD 1). In spite of this a post-dialysis serum total calcium level of $7.3 \mathrm{mg} / \mathrm{dL}$ was recorded for which continuous micro-infusion of $10 \mathrm{ml}$ thrice per day of calcium gluconate $94 \mathrm{mg} / \mathrm{ml}$ [B Braun Melsungen AG Germany] was commenced along with oral supplementation of alphacalcidolum [Alpha D3@, Teva Pharmaceuticals SRL, Romania] $0.50 \mu \mathrm{g}$ twice per day. Thus, during the first postoperative day, the patient received only $2.82 \mathrm{~g}$ of elemental calcium, due to the risk of precipitating calciphylaxis. The laboratory results collected on POD 1 and POD 2 are included in Table 1.

On the second postoperative day (POD 2) the patient presented with rapid and progressive hypocalcae- mia symptoms, i.e. spasm, perioral paraesthesia and tingling of the extremities.

The ionic calcium level measured this time was very low at $2.2 \mathrm{mg} / \mathrm{dL}, \mathrm{nv}: 3.8-4.8 \mathrm{mg} / \mathrm{dL}$. A For this condition we supplemented IV calcium, giving an initial intravenous injection of $10 \mathrm{ml}$ calcium gluconate 94 $\mathrm{mg} / \mathrm{ml}$ [B Braun Melsungen AG Germany] and then 30 $\mathrm{ml}$ of calcium gluconate in continuous micro-infusions four times daily. Within a few hours of the administration of the supplementary calcium, the patient developed atrial fibrillation with tachyarrhythmia (heart rate $>150 / \mathrm{min}$ ), acutely altered mental status and a rapid drop in blood pressure to $70 / 40 \mathrm{~mm} \mathrm{Hg}$.

Norepinephrine [Noradrenaline, $2 \mathrm{mg} / \mathrm{ml}$, Aguettant Ltd, UK] was commenced as intravenous infusion a for haemodynamic support and synchronised cardioversion. Shortly after that, the patient developed asystole, for which cardiopulmonary resuscitation (CPR) was performed for thirteen minutes. After an initial period of no more than ten minutes, when there was a return to sinus rhythm and a slightly hemodynamic amelioration, another cardiac arrest ensued for which standard hospital resuscitation protocol was initiated. External thoracic compressions and ventilation, CPR was performed for thirty minutes during which time a total of $10 \mathrm{mg}$ of epinephrine [adrenaline, Terapia SA, Romania] at $1 \mathrm{mg} / \mathrm{ml}$, was given.

The patient was unresponsive to these resuscitation manoeuvres and died. Before the patient's death, ionic calcium was $3.1 \mathrm{mg} / \mathrm{dL}$.

\section{DISCUSSIONS}

Hypocalcemia after parathyroidectomy is expected to happen but is generally oligosymptomatic and is solved in the first 3-4 days postoperatively. Extending this period of severe hypocalcaemia, possibly accompanied by other ionic disorders such as hypophosphatemia and hypomagnesaemia, defines HBS. Strictly nosologically, within the same syndrome hypocalcaemia immediately after parathyroidectomy may occur, which is based on the same pathophysiological mechanism i.e. the sudden decrease of postoperative iPTH and the impact that the hormone has on the osteoclastic resorption [5].

The prevalence of HBS is contrarily reported in the literature, with figures ranging between 4-95\% depending on several factors, i.e. primary or secondary parathyroid disease, geographic area [6]. The complication occurs more frequently after parathyroidectomy for re- 
nal hyperparathyroidism, where the clinical manifestation of HBS is more severe [7]. Such a case, with rapid fatal development shortly after parathyroidectomy, is presented here. The literature reports relatively few such situations, those reported generally concerning post-surgical treatment of SHPT $[8,9]$.

From the pathophysiological point of view, HBS can be defined as an alteration of the bone remodelling process, which usually removes the osteoclastic activity from the affected bone and replaces it with new bone osteoblastic activity. This balance is lost in primary and secondary hyperparathyroidism, where the increased osteoclastic activity is stimulated by increased secretion of iPTH, which explains demineralisation and hypercalcemia in hyperparathyroidism. The sudden reduction of iPTH levels immediately after parathyroidectomy primes a change in ionic fluxes, with rapid remineralisation of the "starved" bone, and sometimes severe and prolonged reduction of serum calcium and other ions [10]. The syndrome should not be confused with postoperative hypocalcaemia that occurs in other situations such as thyroid surgery or bariatric surgery, where the pathophysiology of the complication is different, i.e. an inadvertent resection of parathyroids, intestinal malabsorption $[11,12]$. Similar ionic disorders including hypocalcaemia, hypokalemia also occur in other postoperative or posttraumatic conditions such as peripheral or abdominal compartment syndrome, rhabdomyolysis, but in these cases, the pathophysiology differs from HBS $[13,14]$.

The literature describes several risk factors for HBS [2]. Among these factors, most authors agree that the presence of preoperative parathyroid-related bone lesions (osteitis fibrosa cystica, brown tumours, pathologic fractures) is significantly associated with the development of postoperative HBS $[15,16]$. In the case described here, there were no X-rays on admission to objectify these signs, but patient described multiple fractures in the disease's history. High levels of preoperative serum AlkPhos is also considered a predictive factor for parathyroid-related bone disease and therefore for HBS [16]; our patient's preoperative serum level of AlkPhos was $376 \mathrm{U} / \mathrm{L}$ (nv: 40-150 U/L). There are also other risk factors for HBS, which were noted in this case: high values of preoperative serum $\mathrm{PTH}$, older age, the increased volume and weight of resected parathyroid glands. As regards this latter aspect, Zamboni \& Folse [17] confirm the positive statistical correlation between the weight of the resected adenomas and the postoperative incidence of hypocalcaemia and HBS.

Surgical interventions indicated in SHPT are subtotal parathyroidectomy or total parathyroidectomy with or without autotransplantation of parathyroid tissue. A total parathyroidectomy with parathyroid autotransplantation in the sternocleidomastoid muscle was performed in the presented case. Regarding the incidence of postoperative HBS, literature does not describe statistical differences between parathyroidectomy techniques. Total parathyroidectomy without autotransplantation was initially credited with a higher risk of postoperative hypocalcemia, which is why the method was abandoned for many years. In recent years, however, various studies have demonstrated that this technique is feasible without higher postoperative morbidity, including hypocalcemia and HBS [18].

Clinical manifestations of HBS are similar with those of severe hypocalcemia: from minor carpopedal spasms, perioral paresthesia, tingling extremities, clinical signs of hypocalcemia (Chvostek, Trousseau) to more severe symptoms such as convulsions, cardiac symptoms, coma and even fatal outcome. Our patient did not experience symptoms of hypocalcemia on the first postoperative day; 24 hours after surgery, however, a sudden cardiac tachyarrhythmia occurs, very likely in the context of hypocalcemia, the ionic calcium determined at the time being very low. Heart rhythm disorders are also a part of classical semiology of hypocalcaemia, in the context of hypocalcemic cardiomyopathy being frequently described QT interval prolongation, tachyarrhythmia or postoperative exacerbation of latent cardiac insufficiency $[19,20]$, as it is probably also the case of the patient presented.

Hungry bone syndrome's treatment is primarily a preventive one. Patients in the risk group may benefit from preoperative administration of vitamin $\mathrm{D}$ or its active metabolites. Boyle et al. [21] showed that the preoperative treatment of severe hyperparathyroidism with calcitriol $\left(1,25(\mathrm{OH})_{2} \mathrm{D}\right)$, started few weeks before parathyroidectomy, significantly reduces the preoperative values of AlkPhos and the need for postoperative calcium administration. Other authors stipulated the beneficial effect of bisphosphonates in reducing preoperative calcium level and postoperative HBS incidence [22]. When HBS diagnosis is established the curative treatment includes administration of elemental calcium, initially consisting of IV calcium gluconate and once the patient can tolerate, oral calcium supplements, 
tailoring the dose and the frequency of administration according to serum calcium level [18].

Several electrical cardiac changes seen during severe hypocalcemia episode due to the same reason, as explained above were not objectively demonstrate in the present case.

\section{CONCLUSION}

HBS is a severe complication of parathyroidectomy in patients with PHPT and SHPT. In the case of SHPT, hungry bone syndrome may by severe, prolonged and sometimes fatal. Generally, HBS symptomatology is that of a mild hypocalcaemia; in some cases, however, the symptomatology includes heart rhythm disturbances with hemodynamic alterations requiring intensive care measurements and even cardiopulmonary resuscitation. Therefore chronic dialysed patients with recent parathyroidectomy should be closely monitored, here including serial serum calcium dosing, for proper substitutive treatment in the hours and days following surgery.

\section{DONFLICT OF INTEREST}

None to declare.

\section{- REFERENCES}

1. Anwar F, Abraham J, Nakshabandi A, Lee E. Treatment of hypocalcemia in hungry bone syndrome: a case report. Int J Surg Case Rep. 2018;51:335-39.

2. Witeveen JE, van Thiel S, Romijn JA, Hamdy NA. Hungry bone syndrome: still a challenge in the postoperative management of primary hyperparathyroidism: a systematic review of the literature. Eur J Endocrinology. 2013;20:45-53.

3. Neagoe RM, Sala DT, Borda A, Mogoantă CA, Muhlfay G. Clinicopathologic and therapeutic aspects of giant parathyroid adenomas- three case reports and short review of the literature. Rom J Morphol Embriol. 2014;55:669-74.

4. Ho Ly, Wong PN, Sin HK, et al. Risk factors and clinical course of hungry bone syndrome after total parathyroidectomy in dialysis patients with secondary hyperparathyroidism. BMC Nephrol. 2017;18:12.

5. Mittendorf EA, Merlino Jl, MC Henry CR. Postparathyroidectomy hypocalcemia: incidence, risk factors and management. Am Surg. 2004;70:114-19.

6. Latus J, Roesel M, Fritz $\mathrm{P}$, et al. Incidence of and risk factors for hungry bone syndrome in 84 patients with secondary hyperparathyroidism. Int J Nephrol Renovasc Dis. 2013;8:131-7.

7. Farese S. The hungry bone syndrome-un update. Ther Umsh.
2007;64:277-80.

8. Hodarkar A, Yang N, Saleh M, Abdin A, Trippett R, Al-Qadi MA. Fatal hypocalcemia due to hungry bone syndrome after total parathyroidectomy. J Endocrinol Diab. 2017;4:1-3.

9. Marques SA, Kakuda AC, Mendacolli TJ, Marques ME. Calciphylaxis: a rare but potentially fatal event of chronic kidney disease. Case report. An Bras Dermatol. 2013;88:44-7.

10. Rodriguez-Ortiz ME, Pendon_Ruiz de Mier MV, Rodriguez M. Parathyroidectomy in dialysis patients:indications, methods and consequences. Semin Dial. 2019 doi: 10.1111/sdi.12772. [Epub ahead of print]

11. Neagoe RM, Cvasciuc IT, Muresan M, Sala DT. Incidental parathyroidectomy during thyroid surgery- risk, prevention and controversies; a review. Acta Endo (Buc). 2017;13:467-75.

12. Neagoe RM, Mureșan M, Bancu Ș, Balmos I, Băișan V, Voidăzan S, Sala D. Results of laparoscopic sleeve gastrectomy-5-year follow-up study in an eastern European emerging bariatric center. Obesity surgery. 2016;27:983-9.

13. Tomlinson L, Holt S. Rhabdomyolysis and Compartment Syndrome. In: Blakeley S. (eds) Renal Failure and Replacement Therapies. Competency-Based Critical Care. Springer, London, 2008.

14. Muresan M, Muresan S, Brinzaniuc K, et al. How much does decompressive laparotomy reduce the mortality rate in primary abdominal compartment syndrome? A single-centre prospective study on 66 patients. Medicine (Baltimore). 2017;96(5):e6006. doi: 10.1097/MD.0000000000006006.

15. Ajmi S, Sfat R, Trimeche S, Ben Ali K, Nouira M. Scintigraphic findings in hungry bone syndrome following parathyroidectomy. Rev Esp Med Nucl. 2010;29:81-3.

16. Jervis L, James $M$, Howe W, Richards S. Osteolytic lesions: osteitis fibrosa cystica in the setting of severe primary hyperparathyroidism. BMJ Case Rep. 2017 doi: 10.1136/bcr2017-220603.

17. Zamboni WA, Folse R. Adenoma weight: a predictor of transient hypocalcemia after parathyroidectomy. Am J Surg. 1986;152:611-15.

18. Neagoe RM, Mureșan M, Voidăzan S, Pașcanu I, Radu CP, Sala DT. Subtotal parathyroidectomy versus total parathyroidectomy with autotransplant in secondary hyperparathyroidism - a single-centre prospective cohort of 43 patients. Endokrinologia Polska. 2016;67:202-9.

19. Kazmi AS, Wall BM. Reversible congestive heart failure related to profound hypocalcemia secondary to hypoparathyroidism. Am J Sci. 2007;333:226-9.

20. Shinoda T, Aizawa T, Shirota $T$, et al. Exacerbation of latent heart failure by mild hypocalcemia after parathyroidectomy in a long-term hemodialysis patient. Nephron. 1992;60:482-6.

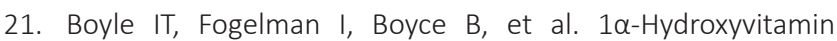
D3 in primary hyperparathyroidism. Clin Endocrinol (Oxf). 19771977;7 Suppl:215s-222s.

22. Jain N, Reilly RF. Hungry bone syndrome. Curr Opin Nephrol Hypertens. 2017;26:250-5. 